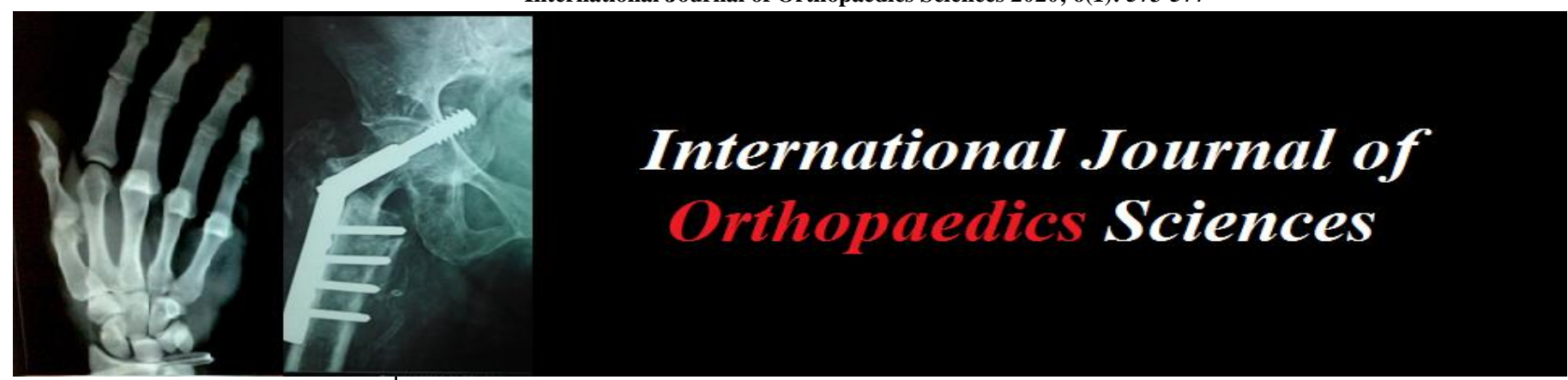

E-ISSN: 2395-1958

P-ISSN: 2706-6630

IJOS 2020; 6(1): 573-577

(C) 2020 IJOS

www.orthopaper.com

Received: 01-11-2019

Accepted: 05-12-2019

Dr. K Shanmuganathan

M.S. Ortho Senior Assistant

Professor, GOVT. Theni Medical

College, Tamil Nadu, India

Dr. D Sounderrajan

M.S Ortho, Senior Resident,

GOVT. Theni Medical College,

Tamil Nadu, India
Corresponding Author: Dr. K Shanmuganathan M.S. Ortho Senior Assistant Professor, GOVT. Theni Medical College, Tamil Nadu, India

\section{Evaluation of clinical and functional outcome of internal fixation with intra medullary interlocking nailing with 'Poller' blocking screws in tibial metaphyseal fractures}

\section{Dr. K Shanmuganathan and Dr. D Sounderrajan}

DOI: https://doi.org/10.22271/ortho.2020.v6.i1k.1927

Abstract

Aim: To evaluate the Clinical and Functional Outcome of Closed Reduction/Open Reduction and Internal fixation with Intramedullary Inter Locking Nailing with "Poller" Blocking Screws" in Tibial Metaphyseal Fractures.

Materials and Methods: This is a prospective study of 20 cases of tibial metaphyseal fractures treated with open reduction/closed reduction with statically locked intra medullary nailing with 'poller screws' done in our Govt Theni Medical College Hospital, between August 2014 and September 2016. In our study, the test used for data analysis is ANOVA test.

Conclusion We conclude that the surgical management of, open reduction/closed reduction with intra medullary interlocking nailing and poller screws in tibial metaphyseal fractures is effective in achieving the fracture alignment with poller screw acting as a reduction tool.

Keywords: Metaphyseal tibial fractures, medullary canal diameter, valgus deformity, varus deformity, recurvatum deformity, poller screw, Intramedullary inter locking nailing

\section{Introduction}

"Poller" screws derived their name from a traffic guiding device used in European cities as it guide and direct the nail in the centre of the medullary cavity. Originally they are $4.5 \mathrm{~mm}$ sized cortical screws.

Biomechanism: In proximal mataphyseal tibial fractures, the fracture is commonly oriented from distal anterior to proximal posterior. Nails used in proximal fractures are not forced anteriorly as occurred in case of mid shaft fractures. Further disparity in the medullary canal diameter between the fragments and the anatomy of metaphysis leads nail to go eccentrically Causing malalignment of valgus/varus or and recurvatum/antecurvatum. In this situation poller screws having its role in reducing the diameter of medullary canal wich inturn prevent the malposition of nail in the cavity. In valgus deformity the poller screw applied anteroposteriorly on the concave side of deformity reduce the medullary canal diameter and act as an substitute for the laterl cortex guiding the nail. Thus it guide the nail when the nail is displaced laterally due to the shape of the medullary cavity and more medial entry of the nail. In the varus deformity with the screw applied on the concave side of the deformity, it act as substitute for the medial cortex thereby centralise the nail in the medullary cavity.

In antecurvatum deformity, mediolaterally placed poller blocking screw essentially functions as a substitute for anterior cortex, keeping the nail centrally in the medullary canal. Thus, the blocking screw placed in the anterior half of the proximal part of the tibia in the sagittal plane blocks the nail from passing anteriorly and abolishing the extension and translational forces in antecurvatum deformitry. The reverse is applied for recurvatum deformity.

Similarly, in distal metaphyseal fractures as the nail passing into the short distal fragment the disparity in the medullary canal diameter between the short distal fragment and the long proximal fragment leads nail to go eccentricaly causing the malalignment. An anteroposterior poller screw placed laterally or medialy decrease the medullary canal diameter and act as substitute for the lateral/medial cortex, keep the nail at midline, and prevent valgus/varus deformity. 


\section{Inclusion and exclusion criteria criteria}

Adult patients more than 20 years of age. Either proximal or distal metaphyseal fractures. Adolescent patients <20yrs of age and Very minimally (or) undisplaced fractures are excluded from the study.

Materials: Intramedullary inter locking nail and 4.5 cortical screws as poller screws

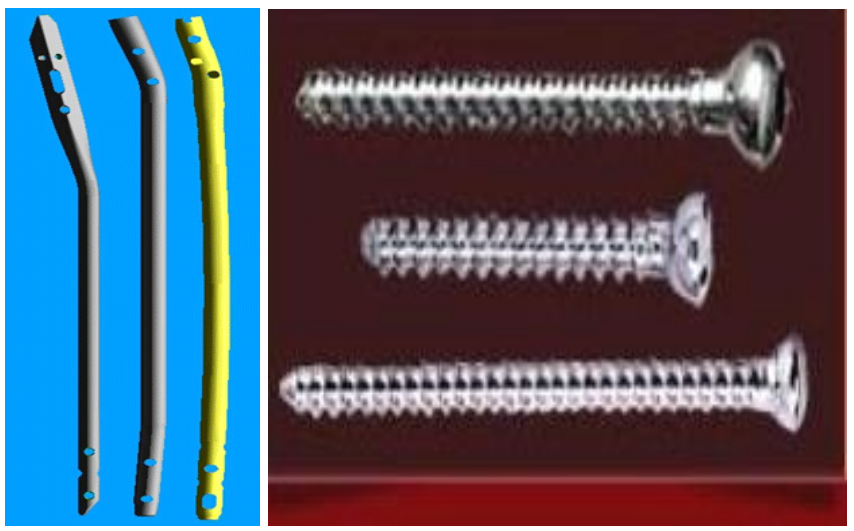

Fig 1: Proximal metaphysic: In recurvatum deformity

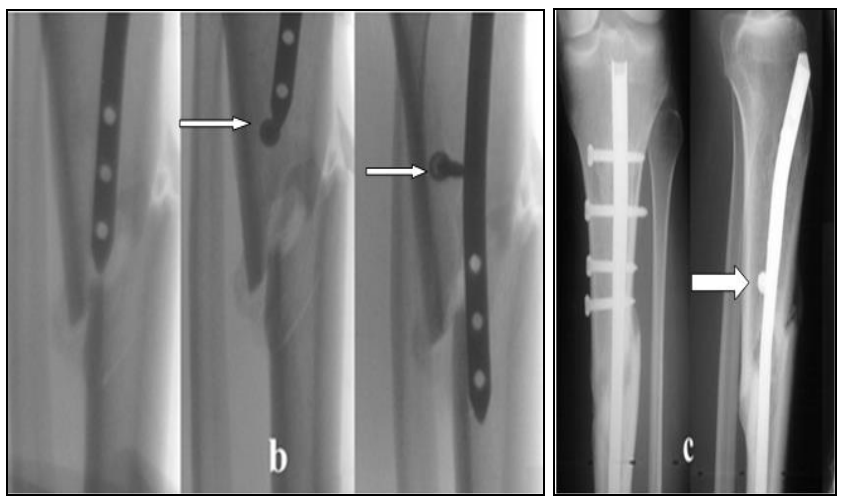

Fig 2: The recurvatum deformity is corrected by the "poller" screw on the mediolateral plane posterior to the nail In valgus deformity:
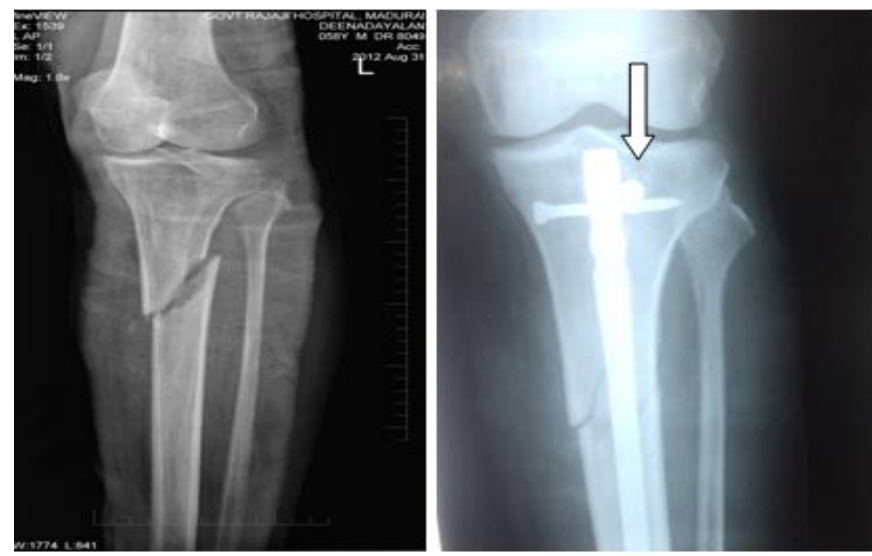

Fig 3: The valgus deformity is corrected by the anteroposterior poller Scr.

\section{Distal metaphyseal fractures}

In valgus deformity: The anteroposterior "poller" screw is put on the lateral side of the nail, on the concave side of the deformity.

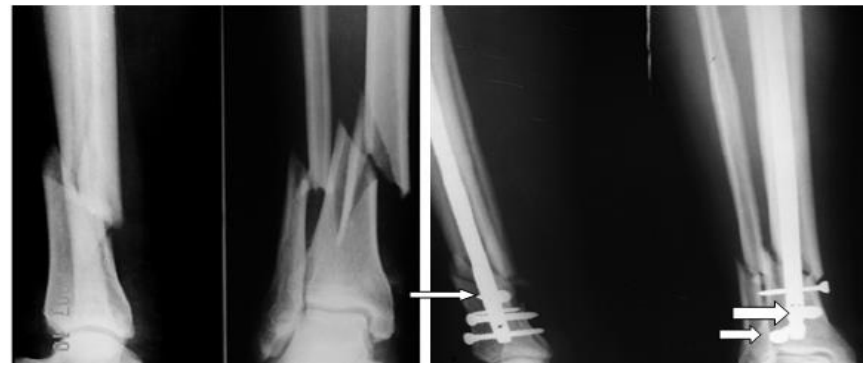

Fig 4: In varus deformity

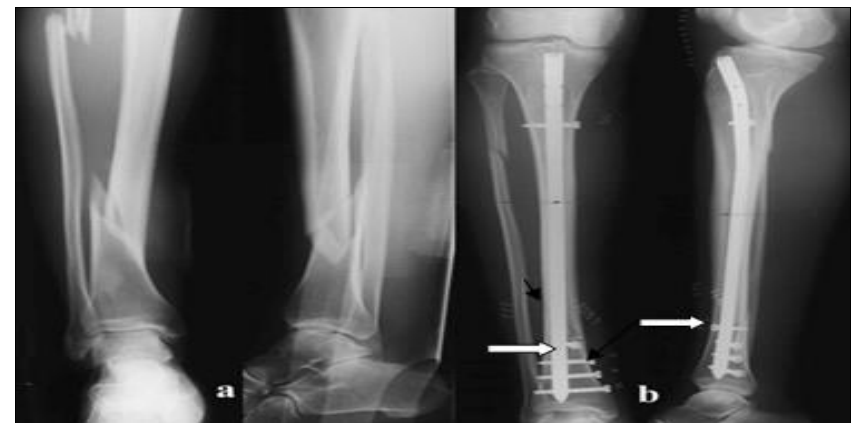

Fig 5: The anteroposterior "poller" screw is put on the concave side of the deformity which is medial to the nail.

Operative Technique All the cases were taken up for surgery under spinal anaesthesia through the patellar tendon splitting approach. During nailing the tendency of the fragment towards for which deformity is noted. The poller screw is inserted under the C-Arm guidance according to the deformity

Table 1: Proximal metaphyseal fractures

\begin{tabular}{|c|c|}
\hline Deformity & Site of poller screw in short fragment \\
\hline Antecurvatum & Anterior to the nail \\
\hline Recurvatum & Posterior to the nail \\
\hline Valgus & Lateral to the nail, at concave side. \\
\hline varus & Medial to the nail, concave side. \\
\hline
\end{tabular}

Table 2: Distal Metaphyseal fractures

\begin{tabular}{|c|c|}
\hline Deformity & Site of poller screw in short fragment \\
\hline Valgus Deformity & Lateral to the nail \\
\hline Varus Deformity & Medial to the nail \\
\hline
\end{tabular}

\section{Karlstrom-Olerud score}

1. Residual angulation: ( 0 to 3 points)

- $0^{\circ} \quad--\quad 0$ point

- 1 to $3^{\circ} \quad--\quad 1$ points

- 4 to $5^{\circ} \quad--\quad 2$ points

- $>5^{\circ} \quad--\quad 3$ points

2. Fracture healing: ( 0 to 3 points)

- Union $<12$ weeks -- 0 point

- Delayed union $>12$ weeks $\quad$-- $\quad 1$ point

- Delayed union requiring -- 2 points secondary procedures

- Non-union > 6 months $\quad$-- 3 points

\section{Cast support: (0 to 1 point)}

- No cast support -- 0 point

- Cast support -- 1 point 


\section{Outcome}

- 0 \& 1 Points

Excellent

- 2 \& 3 Points

Good

- 4 Points

Satisfactory

- 5 Points

Fair

- 6 \& 7 Points

Poor

Patients were evaluated clinically and Radiographically with the anteroposterior and lateral $\mathrm{x}$ rays according to the above Karlstorm-Olerud scoring system

\section{Case No: 1}
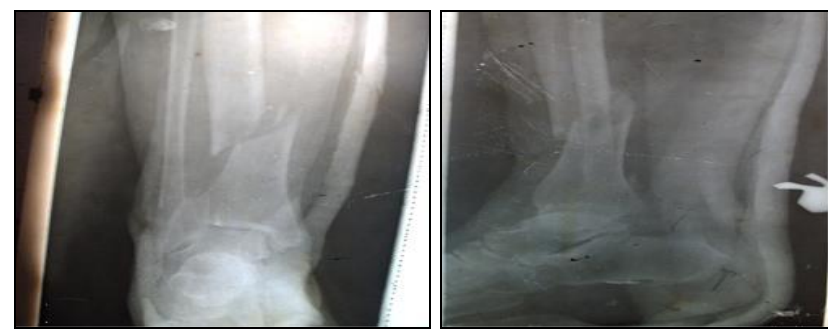

Fig 6: Valgus deformity
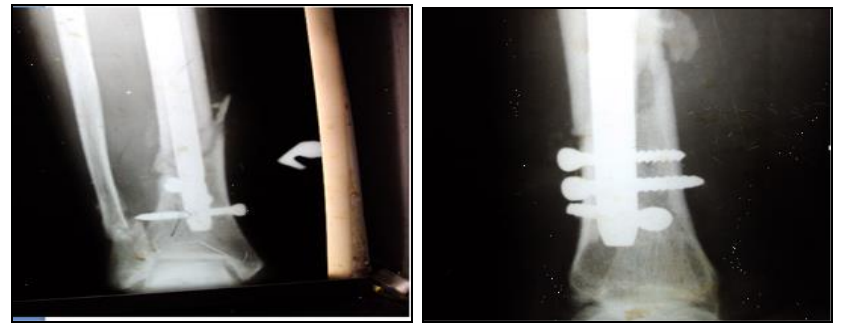

Fig 7: Valgus deformity corrected with anteroposterior poller screw at the concave side of the deformity, lateral to the nail

Case No: 2

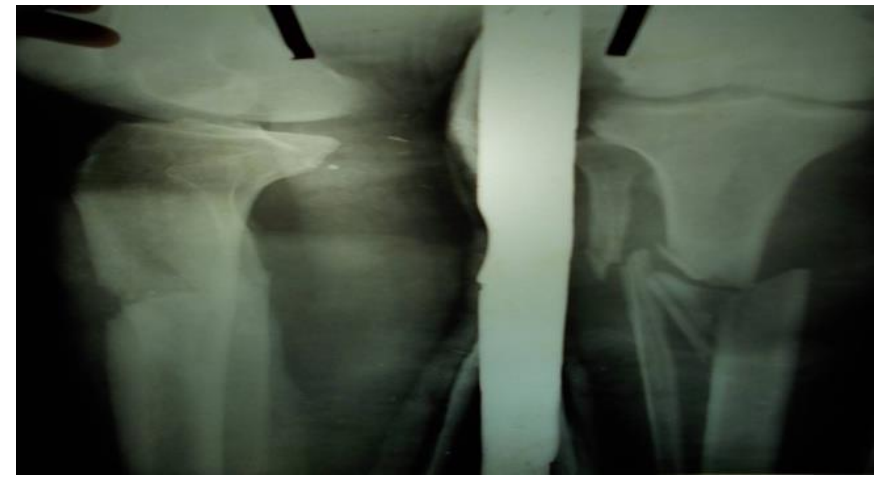

Fig 8: Valgus deformity of the proximal metaphysis

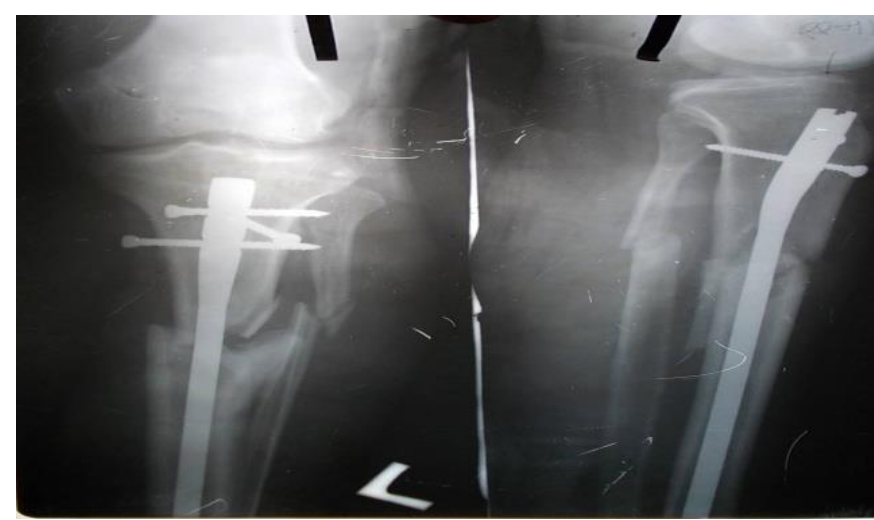

Fig 9: Valgus deformity corrected with anteroposterior poller screw on concave side of the deformity lateral to the nail

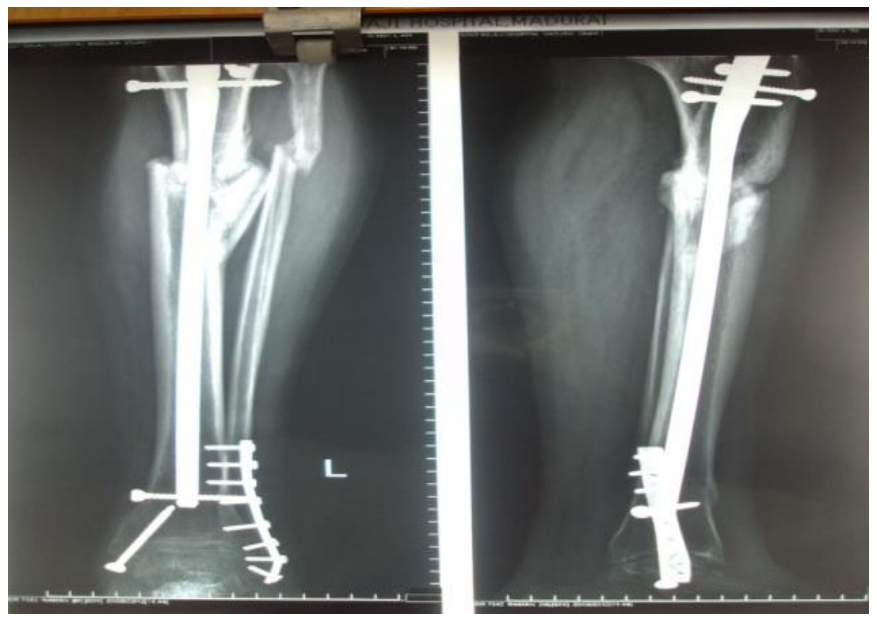

Fig 10: 12 weeks follow up with bone union

\section{Result - analysis}

In our study, the test used for data analysis is ANOVA test. In this method, repeated measures designs allow their own subject to act as control. In our study there was no control group. So the ANNOVA test is chosen for our study. Multiple measurements are made on the same individual at different point of times ${ }^{[24]}$.

\section{Residual angulation}

Table 3: Antecurvatum / Recurvatum (7 legs having the deformity)

\begin{tabular}{|c|c|c|c|c|c|}
\hline & $\mathbf{N}$ & Mean & SD & 95\% LCL & 95\% UCL \\
\hline Pre-operative & 7 & 5 & 2.31 & 4.75 & 5.26 \\
\hline Post-operative & 7 & 1 & 1.92 & 0.95 & 1.05 \\
\hline At Union & 7 & 0.43 & 1.13 & 0.41 & 0.45 \\
\hline
\end{tabular}

Post-operative mean residual antecurvatum/recurvatum alignment is 1(one) degree (95\% LCL is 0.95 degrees, 95\% UCL is 1.05 degrees) when compare to the preoperative mean value of 5 degree (95\% LCL 4.75 degrees, $95 \%$ UCL is 5.26 degrees). The $\mathrm{P}$ value was 0.04 which was $(<0.05)$ statistically significant.

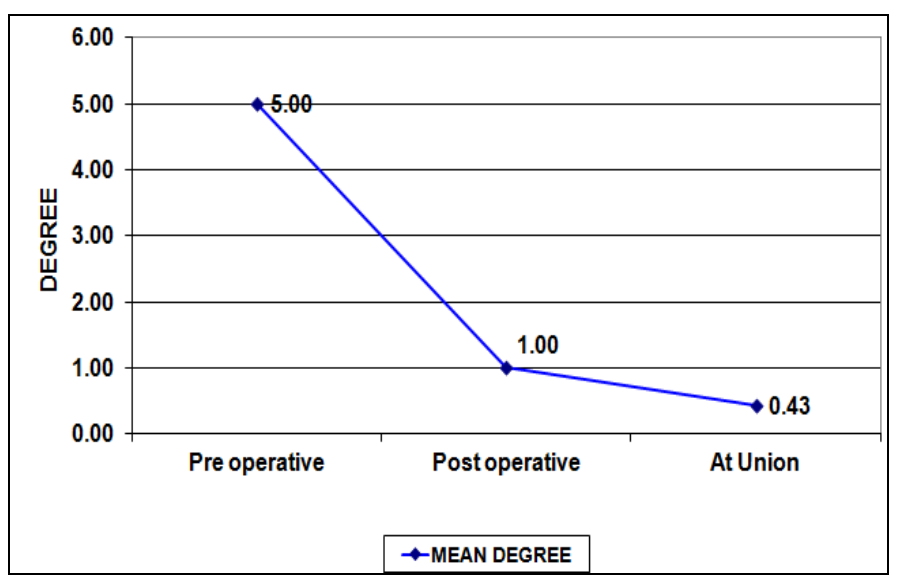

Fig 11: Mean degree

Table 4: Varus/Valgus angulation: (18 legs having the deformity)

\begin{tabular}{|c|c|c|c|c|c|}
\hline & $\mathbf{N}$ & Mean & SD & 95\% LCL & 95\% UCL \\
\hline Pre-operative & 18 & 9.89 & 6.16 & 9.39 & 10.41 \\
\hline Post-operative & 18 & 2.78 & 3.65 & 2.64 & 2.93 \\
\hline At Union & 18 & 1.61 & 2.38 & 1.53 & 1.69 \\
\hline
\end{tabular}

Post-operative residual mean varus/valgus alignment is 2.78 degree (95\% LCL is 2.64 degrees, $95 \%$ UCL is 2.93 degrees) 
when compare to the preoperative mean value of 9.89 degree (95\% LCL 9.39 degrees, 95\% UCL is 10.41 degrees). The $\mathrm{P}$ value is $0.02(<0.05)$ which is statistically significant.

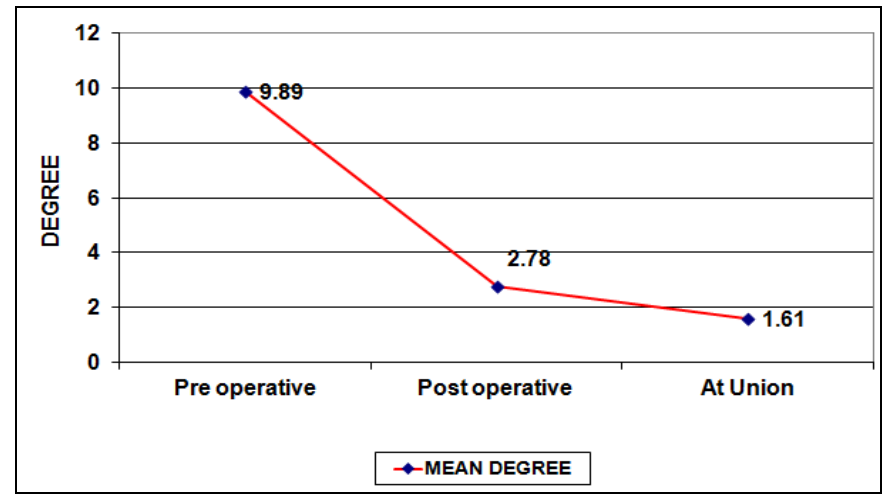

Fig 12: Valgus-varus

Table 5: Time taken for fracture union

\begin{tabular}{|c|c|c|}
\hline Time for union & No. of cases & Percentage \\
\hline$<15$ weeks & 12 & 60 \\
\hline $15-20$ weeks & 7 & 35 \\
\hline$>20$ weeks & 1 & 5 \\
\hline Total & 20 & 100 \\
\hline
\end{tabular}

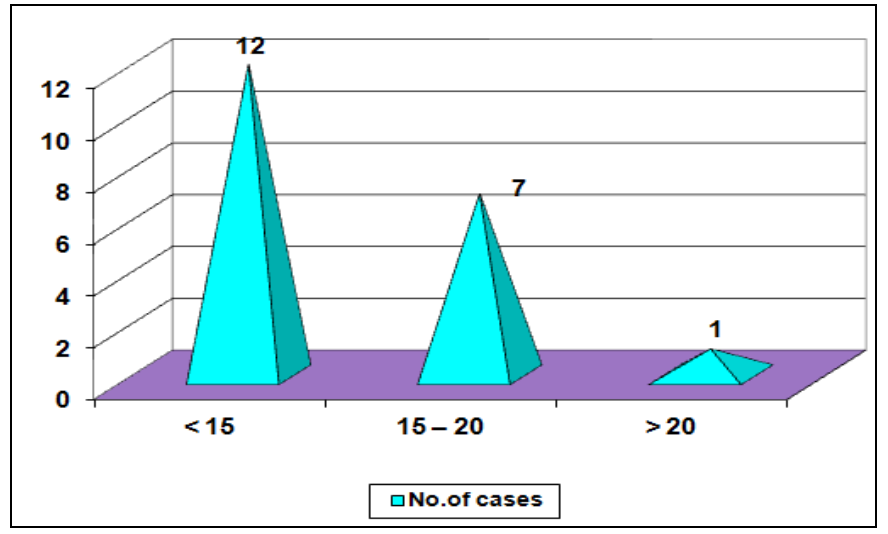

Fig 13: Time for union

Table 6: Karlstorm-Olerud Scoring

\begin{tabular}{|c|c|c|c|}
\hline Score & No. of cases & Percentage & Remarks \\
\hline 0,1 & 12 & 60 & Excellent \\
\hline 2,3 & 6 & 30 & Good \\
\hline 4 & 0 & 0 & Satisfactory \\
\hline 5 & 1 & 5 & Fair \\
\hline 6 & 1 & 5 & Poor \\
\hline
\end{tabular}

Table 5: The Karlstrom-Olerud score in 12 patients is Excellent, in 6 patient is Good, in One patient is satisfactory and in One patient is Poor. $95 \%$ of the patients are having the excellent to satisfactory outcome.

\begin{tabular}{|c|c|c|}
\hline $\mathbf{G}$ & $\mathbf{6}$ & $\mathbf{3 0 \%}$ \\
\hline $\mathrm{S}$ & 1 & $5 \%$ \\
\hline $\mathrm{P}$ & 1 & $5 \%$ \\
\hline Total & 20 & $100 \%$ \\
\hline
\end{tabular}

\section{Discussion}

The metaphyseal fracture are having the coronal and sagittal malalignment due to the disparity in the medullary canal diameter of the proximal and distal fragments and due to anatomy of the medullary canal particularly in case of the proximal metaphyseal fractures..In our study we taken the method of using of the poller screw in metaphyseal fracture.
The disparity between the diameters of medullary canal at the level of isthmus (i.e. maximum possible nail size) and at the fracture site in all cases. We found that there was a significant $\mathrm{p}$ value $<0.001(p<0.5)$ which is significant in comparing the diameter. We found that the mean diameter of medullary canal at the level of isthmus was $9.90 \mathrm{~mm}$ compared to 18.25.2mm at the level of fracture site. This mismatch in the medullary canal diameter is the cause for the malalignment in intramedullary nailing. We emphasized that the use of poller screw as reduction tool was proved in our study by the repeated measures ANOVA test with $95 \%$ of Excellent to satisfactory outcome which is better the values given by the C. Krettek et al. The C. Krettek et al. showed the result of 94\% excellent to satisfactory outcome. In our study, the mean postoperative mean varus/valgus angulation is 2.78 degrees in comparing to the mean preoperative varus/valgus of the 9.89 degrees and postoperative mean antecurvatum/recurvatum deformity is 1 degree (one) in comparing to the preoperative value of the 5 degrees. The poller screws usually applied in anteroposterior direction as the coronal plane malalignment is more prone to occur than the sagittal plane. In case sagittal plane deformities is expected to occur mediolateral screw also was inserted, even in single patient. In one patint we have applied both antero posterior and mediolateral screws to prevent both the varus and recurvatum deformity. In another patient with varus deformity two screw were inserted. The reduction was ensured in two planes with C-Arm after placing the poller screws and before applying the locking screw We had excellent to satisfactory outcome in $95 \%$ of patients by Karlstrom-Olerud scoring which is better than the results of C. Krettek et al. with $94 \%$ excellent

\section{Conclusion}

Poller screws

- Are effective in achieving the fracture alignment with poller screw acting as a reduction tool

- Give improved stability of the bone - implant construct, with the poller screw functionally reducing the medullary width.

\section{Reference}

1. Sean E Nork, David P Barei, Thomas A schildhauer et al Intramedullary nailing of proximal quarter tibial fractures J Orthop Trauma. 2006; 20(8):523-8.

2. Krettek C, Stephen C, Schandelmaier P et al. The use of poller screws as blocking screws in stabilizing tibial fractures with small diameter intramedullary nails. JBJS (Br). 1999; 81-B:963-8.

3. Mueller ME, Nazarian S, Koch P, Shatzker J. The comprehensive classification of fractures of long bones: Berlin etc, Springer Verlag, 1990.

4. Campbell's Operative Orthopedics 10th edition, 2003: volume 3, 2671-73, 2705, 2754-57, 2760.

5. Rockwood and Greens Fractures in Adults, 4th edition, 1996; 2:2140-41, 2155-61.

6. Digby JM, Hollowary GMN, Webb JK. A study of function after tibial cast bracing. Injury. 1982-83; 14:4329.

7. Haines JF, William EA, Hargadon ES. Is conservative treatment of tibial fractures justified? JBJS (Br). 1984; 66-B:84-8.

8. Bruce French, Paul Tornetta. High energy tibial shaft fractures. Orthopedic Clinics of North America. 2002; 33(1):211-230.

9. Cole PA, Zowodzki M, Krejor PJ. Less invasive skeletal 
stabilization system for fractures of proximal tibiaIndications, surgical technique and preliminary results of UMC clinical trial. Injury. 2003; 34A:16-29.

10. Im GI, Tae Sk. Distal metaphyseal fractures of tibia: A prospective randomized trial of closed reduction and intramedullary nail versus open reduction and plate and screws fixation. J Trauma, 2005, 59(5). 